\title{
Le véritage
}

\section{Craig Maltais}

Tout le monde en a créé

Dans le paysage sans aucune pensée.

Tout le monde en a créé

Tout le monde en a perdu Dans les villes pleines d'individus

Tout le monde en a perdu

Tout ce qu'on n'a jamais dit Dans la forêt - on espère interdit

Tout ce qu'on n'a jamais dit

Tout ce qu'on a oublié

Dans les vents, chuchoté

Tout ce qu'on a oublié

Tout le monde a des vérités

Dans la nature, elles sont partagées

Tout le monde a des vérités

Tout le monde a un héritage

Dans le ciel, flottant dans les nuages

Tout le monde a un héritage

Tout ça j’appelle : le véritage 